\title{
Development of LORL evaluation method and its application to a loop-type sodium-cooled fast reactor
}

\author{
Yuya IMAIZUMI*, Fumiaki YAMADA*, Mitsuhiro ARIKAWA**, Hiroki YADA* \\ and Yoshitaka FUKANO* \\ *Japan Atomic Energy Agency \\ E-mail: imaizumi.yuya@jaea.go.jp \\ ${ }^{\star \star N} \mathrm{NESI}$ inc. \\ Shiraki-1, Tsuruga, Fukui 919-1279, Japan
}

Received: 16 February 2018; Revised: 9 May 2018; Accepted: 12 June 2018

\begin{abstract}
The loss-of-reactor-level (LORL) where the coolant circulation path is lost is one of the important accident types of loss-of-heat-removal-system (LOHRS) in loop-type sodium-cooled fast reactors (SFRs). Due to the non-negligible possibility obtained by probabilistic risk assessment (PRA), pipe failures and succeeding sodium leakage in two points both occurred in primary heat transport system (PHTS) was assumed in this study, unlike the conventional studies assuming single pipe failures. The sodium level in reactor vessel (RV) is affected by many elements such as leakage position, guard vessel volume, operational state of pumps, and countermeasures to maintain sodium level which are sodium pump-up into RV and siphon-breaking of the pipe between RV and pump. Thus, a calculation program was developed in this study to evaluate and discuss the effectiveness of the countermeasures and safety margins for the loss of coolant circulation path. In addition, the crack size was discussed and evaluated realistically, and $t^{2}(t$ : pipe thickness) was obtained for a sufficiently conservative value, instead of $D t / 4$ ( $D$ : pipe diameter) that was assumed in the conventional studies. Time interval between two leakages was also given by PRA, considering failure rates of the pipes and components. Representative sequences and leakage positions where the sodium level can decline below emergency sodium level (EsL) were chosen, and the sodium level transient in RV was calculated where the crack size of the second leakage was set $t^{2}$. The calculations were also conducted where the larger crack size, $D t / 4$, was set for both the first and second leakage, in order to investigate additional requirements to maintain the RV sodium level. The evaluation results clarified that the coolant circulation loop can be maintained even after the second leakage in PHTS, taking into account the effects by the countermeasures.
\end{abstract}

Keywords : Coolant leakage, Severe accident, Sodium-cooled fast reactor, Loss-of-reactor-level (LORL), Safety evaluation method

\section{Introduction}

Sodium-cooled fast reactors (SFRs) are operated at low internal pressures, and the operating temperature of the sodium has a sufficient margin below the boiling point. Owing to the feature of low internal pressure, pipe break of rapid spreading type cannot occur, and the hypothetical leak can be terminated in early stage of the leakages, without any depressurization boiling or significant coolant loss in reactor vessel (RV). Therefore, one of the requirements to prevent loss-of-heat-removal-system (LOHRS) in loop-type SFR is retention of RV sodium level above emergency sodium level (EsL), which is necessary to maintain coolant circulation through RV. Figure 1 shows the primary heat transport system (PHTS), and alternative decay heat removal system (ADHRS) which can be used for the sodium level retention.

In order to restrict the leakage volume, preventive design is adopted generally in loop-type SFRs. In Monju, the sodium level above EsL in RV can be maintained by the design of highly positioned primary coolant pipes, and guard 


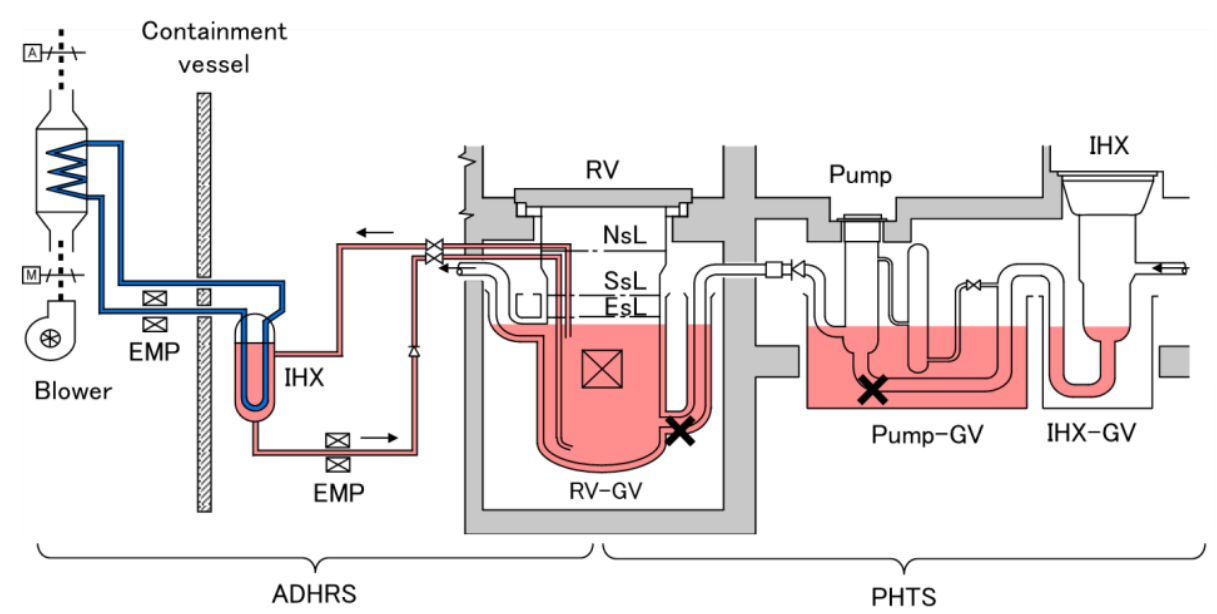

Fig. 1 PHTS and ADHRS in Monju, and leakage positions assumed in the calculation. The sodium level declined below EsL in this figure because of the leakages.

vessels (GVs) below the RV, pipes, pumps, and intermediate heat exchangers (IHXs). In the experimental reactor Joyo and commercialized reactor in the stage of conceptual design, Japan Sodium-cooled Fast Reactor (JSFR), which are different SFRs of loop-type, the leakage volume is restricted by outer pipes around the primary coolant pipes (Ishikawa, et al., 2009, Kurisaka, 2006).

In the evaluation of core coolability for design basis accident (DBA), single pipe failure of crack-shape has been assumed conventionally for the cause of coolant leakage in PHTS. In addition, coolability in severe accident (SA) which was caused by a hypothetical guillotine-type rupture has also been evaluated for Monju to investigate the safety margin of the DBA. As a result, it has been confirmed that severe core damage can be prevented even in the accident of that type (Yamada, et al., 2015).

However in July 2013, requirements for evaluation of SA were added on the new regulatory requirements of Japan, based on the accident of TEPCO's Fukushima Dai-ichi nuclear power station in March 2011.This revision raised a need of SA evaluation for Monju (Advisory Committee on Monju Safety Requirements, 2014, JAEA, 2015) in which the accident was caused by a second coolant leakage in PHTS, besides the SA caused by the abovementioned guillotine-type ruptures. The second coolant leakage in that assumes that occurs in cold standby after the first coolant leakage and succeeding reactor shutdown. According to the result of probabilistic risk assessment (PRA), the frequency of second leakage which can induce LORL is not negligible. In Joyo or JSFR, on the other, the second coolant leakage does not induce LORL unlike the case in Monju, owing to the preventive design of PHTS (Ishikawa, et al., 2009, Kurisaka, 2006).

The sodium level transient after the leakage is affected by many elements, such as height of the leakage position, sodium level in RV and GV, operational state of the pump, and countermeasures described later for the retention of sodium level in RV. In addition, that calculation needs to simulate the transient in long time across several days. On the other hand, complicated heat balance between reactor and its surroundings is not required for that. Considering these backgrounds and requirements, relatively simple calculation program which can include effects from the countermeasures for sodium level retention was developed in this study. This calculation program with favorable operability for the function installations concerning abovementioned countermeasures can be distinctive from ordinal analysis codes such as Super-COPD (Yamada, et al., 2014) which are specialized in synthesized calculations about fluid dynamics and heat transfers.

\section{Selection of representative sequences for the coolant leakages 2.1 Assumption for leakage positions}

Figure 2 shows the coolant leakage positions which were chosen and considered in this study for PHTS of Monju. In the case of coolant leakages where the second coolant leakage occurred in a pipe of high position above system sodium level (SsL), the RV sodium level for the coolant circulation in intact loops can be maintained by nitrogen inflow through the pipe crack and succeeding interruption of the flow-out from RV. On the other hand, in the case 


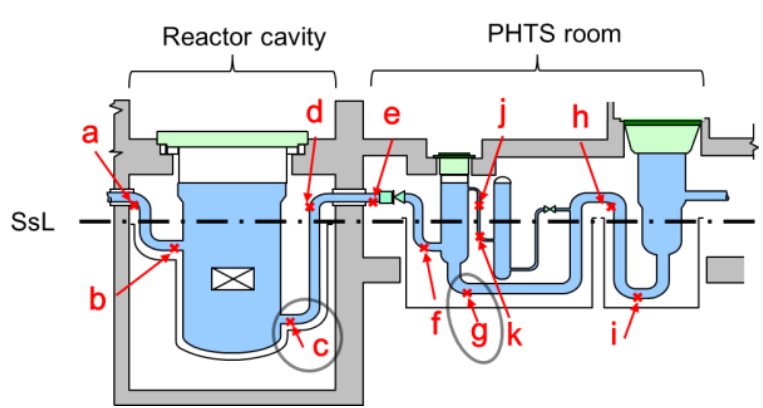

Fig. 2 Possible leakage positions considered and selected in this study.
Table 1 Selection of leakage positions for representative sequences.

\begin{tabular}{|c|c|c|c|c|c|}
\hline \multicolumn{2}{|c|}{$\begin{array}{l}\text { Positions for } \\
\text { first leakage }\end{array}$} & \multicolumn{2}{|c|}{ Positions for second leakage } & \multirow[t]{2}{*}{$\begin{array}{l}\text { Declining } \\
\text { below EsL }\end{array}$} & \multirow[t]{2}{*}{$\begin{array}{c}\text { Final } \\
\text { selectior }\end{array}$} \\
\hline \multirow{3}{*}{$\begin{array}{l}\text { Reactor } \\
\text { cavity }\end{array}$} & \multirow{3}{*}{$\begin{array}{l}\text { Inside } \\
\text { RV-GV }\end{array}$} & $\begin{array}{l}\text { Reactor } \\
\text { cavity }\end{array}$ & Inside RV-GV & & \\
\hline & & \multirow{2}{*}{$\begin{array}{l}\text { PHTS } \\
\text { room }\end{array}$} & Inside IHX-GV & + & \\
\hline & & & Inside pump-GV & + & + \\
\hline \multirow{3}{*}{$\begin{array}{l}\text { PHTS } \\
\text { room }\end{array}$} & \multirow{3}{*}{ Inside GV } & $\begin{array}{l}\text { Reactor } \\
\text { cavity }\end{array}$ & Inside RV-GV & + & + \\
\hline & & \multirow{2}{*}{$\begin{array}{l}\text { PHTS } \\
\text { room }\end{array}$} & Inside IHX-GV & + & \\
\hline & & & Inside pump-GV & + & \\
\hline
\end{tabular}

where the second coolant leakage occurred in a pipe of low position in GV, all the circulation path of PHTS loops can be lost by the declining below EsL after the second coolant leakage.

\subsection{Representative sequences}

Except the case of leakage above SsL which does not induce sodium level declining below EsL, combinations of the possible coolant leakage positions considered in this study and the selection result are shown in Table 1. The cases where the sodium level can decline below EsL is limited in five cases shown in Table 1. Considering GV volume, height of the leakage positions, and the result of parameter survey which is described later, following two cases were selected as representative cases. The leakage positions selected and assumed in the calculation are "c" and "g" in Fig. 2 , and those are shown in Fig. 1.

Case-A: Leakage in RV-GV at first, that in pump-GV in second

Case-B: Leakage in pump-GV at first, that in RV-GV in second

In RV-GV, RV inlet pipe is representative because of its low height and the pump head which corresponds to core pressure loss. The leakage in pump-GV was selected rather than that in IHX-GV due to the larger internal volume of the pump-GV. In pump-GV, the leakage position which gives the fastest leak rate was chosen by the calculation program which was developed in this study.

As a result of the survey where the crack size was $D t / 4$ (section 2.4 ), the leak rate of $59 \mathrm{~m}^{3} / \mathrm{h}$ that was obtained in the case of pump inlet was larger than that of $24 \mathrm{~m}^{3} / \mathrm{h}$ in the case of pump outlet. One of the reasons of that is the dominant hydrostatic pressure in the pipe rather than the pump head pressure by the low-speed pony motor. The second reason is the small crack size and small leak rate of the outlet pipe which has small pipe diameter and small pipe thickness.

\subsection{Time interval for the two leakages}

The time interval of the leakages was set 24 hours in this analysis. In case the second leakage occurred within 24 hours after the first leakage, the sodium melting mentioned in section 3.2 as a preparation for the siphon-breaking may not be completed, and the decay heat and core temperature can still be high. However, in the result of PRA, the possibility of the sequence where the sodium level decreased below EsL within 24 hours from the first leakage was sufficiently small as shown below. Thus, the time interval of the two leakages in this study was set to be 24 hours.

The failure rates of the pipes and components which can cause leakages were statistically estimated by their integral operation time and failure records which were obtained from a component reliability database system for SFRs, named "CORDS" (Kurisaka, 1996). Based on the failure rates, pipe length, and the number of components that need to be considered, occurrence frequency for first leakage and probability of second leakage within 24 hours from the first leakage were calculated. Occurrence frequency for the combination of first and second leakages was obtained by multiplying them. Even assuming two leakage occurrences within 24 hours, the sodium melting mentioned above can be completed, when the leak rates were so small that RV sodium level declined below EsL after 24 hours. Then, the probability that the leak rates are large enough to induce LORL within 24 hours from the first leakage was calculated by taking into account the probability distribution on the leak rate (Kurisaka, 2011). As a result, the frequency of LORL 
Table 2 Evaluation conditions and results for the pipe crack opening area.

\begin{tabular}{|l|l|l|l|l|l|}
\hline & $\begin{array}{l}\text { Internal } \\
\text { pressure } \\
\text { of the } \\
\text { pipe }\end{array}$ & $\begin{array}{l}\text { Crack } \\
\text { length }\end{array}$ & $\begin{array}{l}\text { Crack } \\
\text { width }\end{array}$ & \multicolumn{2}{|l|}{ Crack opening area } \\
\cline { 5 - 6 } & Variables & $\begin{array}{l}\text { Values for } \\
\text { RV inlet } \\
{\left[\mathrm{mm}^{2}\right]}\end{array}$ \\
\hline $\begin{array}{l}\text { DBA } \\
\text { analysis }\end{array}$ & $\begin{array}{l}\text { Nominal } \\
\text { condition }\end{array}$ & $\mathrm{D} / 2$ & $\mathrm{t} / 2$ & $\mathrm{Dt} / 4$ & 2179 \\
\hline $\begin{array}{l}\text { Evaluation } \\
\text { in this } \\
\text { study }\end{array}$ & $\begin{array}{l}\text { Low } \\
\text { pressure } \\
\text { by a pony } \\
\text { motor }\end{array}$ & $12 \mathrm{t}$ & $\begin{array}{l}\text { Smaller } \\
\text { than } \\
0.01 \mathrm{t}\end{array}$ & $\begin{array}{l}\text { Much } \\
\text { smaller } \\
\text { than } \mathrm{t}^{2}\end{array}$ & $204\left(\mathrm{t}^{2}\right)$ \\
\hline
\end{tabular}

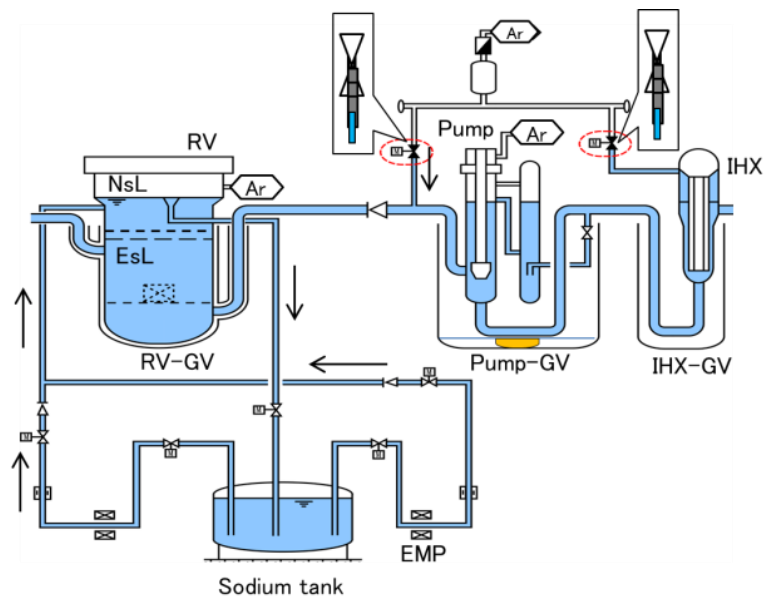

Fig. 3 Sodium pump-up and siphon-breaking.

within 24 hours from the first leakage due to the second leakage was $\sim 8 \times 10^{-9}$ per reactor year.

\subsection{Pipe Crack Size}

Due to the low internal pressure and stable environment of the pipes for SFRs, the pipe failures can be limited to those by fatigue or creep-fatigue, rather than unstable fractures. In "Monju", leakage caused by pipe crack by fatigue was assumed at the crown of elbow in RV inlet. In the DBA analysis, Leak-Before-Break (LBB) (IAEA, 2004) was demonstrated, and the crack size was set $D t / 4$ ( $D$ : pipe diameter, $t$ : pipe thickness). The LBB is the concept where the leakage occurs before the break without any unstable fracture of the pipe, owing to the material ductility. In this study, while the crack size of $D t / 4$ was assumed for the first leakage as well as the DBA analysis, more realistic crack size was discussed for the second leakage. The second leakage is categorized in beyond-DBA (BDBA) where the realistic evaluation rather than conservative one is conducted.

The evaluation condition and result about the crack size is shown in Table 2. As a result of the conventional analysis on crack length growth for SUS304, the crack length when it is penetrated was decided by membrane-bending stress ratio. The maximum value by the analysis is $12 t$ at a pure bending stress field (IAEA, 2004). This was also confirmed by experiments (Garcia-Rodriguez and Sakakibara, 2014) under the condition simulating the plant operational state. In the DBA analysis, the crack length of $12 t$ was substituted by $D / 2$ which can be applied when value of $D / t$ was no less than 24 .

The crack width was evaluated conventionally as $t / 2$ (IAEA, 2004) for the Moderate Energy Fluid System piping (U.S. Nuclear Regulatory Commission, 1990), and that was assumed in the DBA analysis. For the case of second leakage, the crack width was evaluated that it is sufficiently smaller than $t / 100$ based on the report of EPRI (Kumar, et al., 1981) under the plant condition with a low internal pipe pressure after the reactor shutdown.

The crack opening area can be obtained by multiplying the crack length, $12 t$, and the crack width, $t / 100$, assuming rectangular crack shape conservatively. Taking into account some additional conservativeness, the crack size of $t^{2}$ can be obtained. For the RV inlet pipes, the value of $t^{2}$ is less than 0.1 times $D t / 4$ as shown in Table 2.

\section{Countermeasures after the second leakage}

The countermeasures for sodium level retention are sodium pump-up into RV, and siphon-breaking of the pipe between RV and pump which are described below.

\subsection{Sodium pump-up}

For the sodium level retention in RV, the pump up system from over-flow tank into RV which is driven by electromagnetic pump is activated (Fig. 3). Requirements for the pump-up system are below.

i. High pump-up rate which exceeds the leakage rate to prevent declining below EsL. 


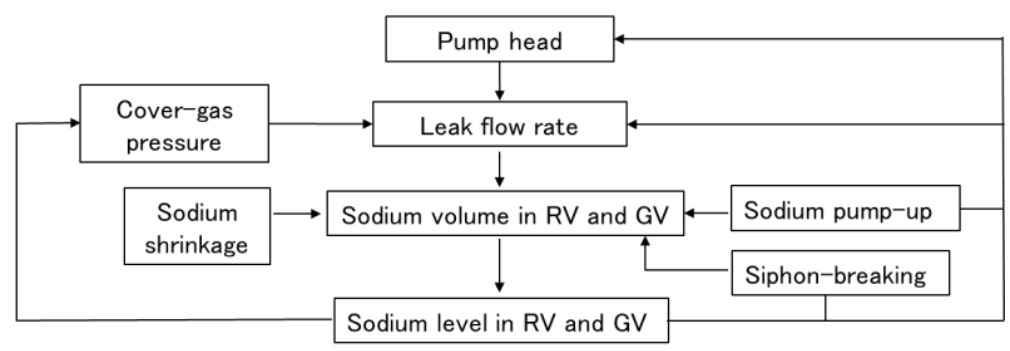

Fig. 4 Schematic diagram for the calculation model.

ii. Two activation modes consisting of a manual mode and an automated mode by the interlock system to prevent declining below EsL.

iii. Enough time for accident recognition, judgement, and operation by operators until the system activation. This can be obtained by emergency drills.

iv. Diversity and redundancy of the electromagnetic pumps by placing them in individual compartment to avoid the effect from the leakage.

v. Monitoring of RV sodium level and stopping of the pump-up system to prevent sodium exhaustion of the tank or overflowing out of GV. The sodium in the leakage loop is drained out to flow it into RV.

vi. Availability of ADHRS in case the pump-up system through the over-flow pipe is unavailable.

\subsection{Siphon-breaking operation}

In the case where the leakage occurred in pump-GV or IHX-GV, the sodium outflow from RV can be stopped by the operation of siphon-breaking. This is conducted by argon gas inflow into the leakage pipe between RV and pump. For the gas inflow, heating and melting of the solidified sodium near the vent valve is necessary (Fig. 3). The sodium is frozen ordinary to prevent unintentional argon gas inflow. After the sodium melting, the gas flows into the pipe by opening the vent valve. Requirements for the siphon-breaking system are below.

i. Enough time for the heating and melting of the frozen sodium near the vent valve. This requires eight hours in normal conditions. The melting is conducted beginning from the RV side, ending in the vent valve side.

ii. Sufficiently slow opening rate of the vent valve to avoid sodium inflow into the vent pipe which is prohibited in that.

iii. Enough time for the accident recognition, judgement, and operation until the system activation. This also can be obtained by emergency drills or routine inspections.

\section{Calculation program for sodium level transient \\ 4.1 Functions in the program}

The functions shown below are embedded in the calculation program which was developed in this study. Figure 4 shows the schematic diagram of the program.

\subsubsection{Pump head}

Due to the pump operation, pressure difference is generated between inlet and outlet pipe of the pump. The pressure difference roughly corresponds to the pressure loss through the core. In the case of leakage in RV inlet, the pressure difference must be taken into account for the conservative evaluation of the leak rate. The pressure difference including that in RV inlet pipe which is dependent on active pump number, operational state of the pumps, and leakage position was obtained by correlations between that and flow rate. In the calculation program, the pressure difference,

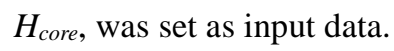

\subsubsection{Leak flow rate}


The leak rate into GV which is dependent on inner/outer pressure difference of the leakage pipe, pipe crack size, and leakage coefficient was calculated in a following leakage model for an orifice.

The leak rate, $Q_{\text {leak }}$, is obtained by

$$
Q_{\text {leak }}=A_{B} \cdot V_{B}
$$

where $A_{B}$ is the pipe crack opening area, and $V_{B}$ is the leak flow speed. The $V_{B}$ was obtained by

$$
V_{B}=\operatorname{sgn}(\Delta H) \sqrt{\frac{2 g \Delta H}{C}}
$$

where $\Delta H$ is the corresponding height of sodium for inner/outer pressure difference in the leakage point. The $g$ is gravitational acceleration. The $C$ is flow resistance coefficient of the leakage point, which was obtained from "Handbook of Hydraulic Resistance" (Idelchik, 1986).

The inner pressure of the pipe was obtained by the sum of the cover-gas pressure, $P_{C G}$, the sodium head pressure, and the aforementioned pressure difference, $H_{\text {core }}$. The outer pressure of the pipe is the atmospheric pressure, $P_{A T M}$, when the GV sodium level, $H_{G V}$, was lower than the height of leakage point, $H_{B}$. Using sodium density, $\rho$, and RV sodium level, $H_{R V}$, the corresponding height of inner/outer pressure difference, $\Delta H$, was given by

$$
\Delta H=\frac{P_{C G}-P_{A T M}}{\rho g}+H_{R V}-H_{B}+H_{\text {core }}
$$

When the sodium level in $\mathrm{GV}, H_{G V}$, was higher than the leakage position, $H_{B}$, the outer pressure of the pipe is the sum of the atmospheric pressure and the sodium head pressure. Then, the corresponding height of pressure difference was given by

$$
\Delta H=\frac{P_{C G}-P_{A T M}}{\rho g}+H_{R V}-H_{G V}+H_{c o r e}
$$

\subsubsection{Sodium volume and sodium level in RV and GV}

The RV sodium volume, $V_{R V}$, was given by the following time-differential equation.

$$
\frac{V_{R V}(t+\Delta t)-V_{R V}(t)}{\Delta t}=-Q_{\text {leak }}-Q_{s}+Q_{O F}+Q_{S B}
$$

The $t$ is the elapsed time, and $Q_{s}, Q_{O F}$, and $Q_{S B}$ are sodium volumetric change rate by the temperature change, pump-up as a countermeasure, flow from RV upper pipes into RV, respectively.

The sodium volume in $\mathrm{GV}, V_{G V}$, was calculated as well by the equation below.

$$
\frac{V_{G V}(t+\Delta t)-V_{G V}(t)}{\Delta t}=Q_{\text {leak }}
$$

The sodium level in RV and GV was obtained by the relationship between sodium level and coolant inventory. The volumetric change rate, $Q_{s}$, by the sodium temperature change is calculated according to the sodium amount in RV, $V_{R V}$, and that in $\mathrm{GV}, V_{G V}$.

\subsubsection{Cover-gas pressure}

Cover-gas pressure was calculated considering cover-gas space change by the sodium level declining. The volume for cover-gas becomes confined by valve closure when RV sodium level declined a certain level. After that, the cover-gas pressure was calculated assuming isothermal process of ideal gas. When the RV sodium level declined, and the cover-gas space expanded, the cover-gas pressure decreases, and the RV sodium level is raised compared to the case of constant cover-gas pressure.

\subsubsection{Effects by countermeasures}




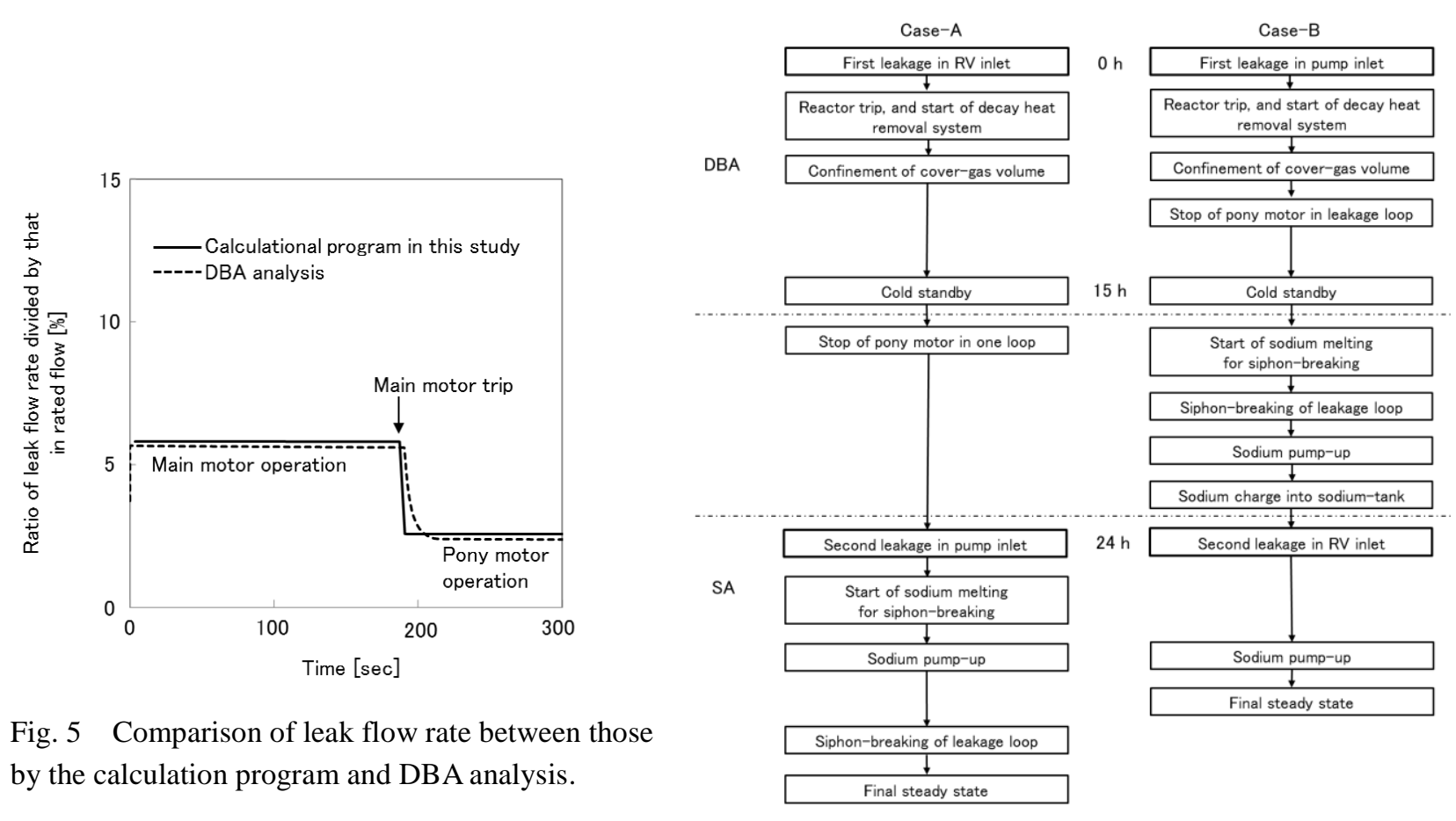

Fig. 6 Event sequences for the two cases.

For the pump-up, the start/stop characteristics of the pump, and pump-up flow rate were given as input data. After the siphon-breaking, some amount of sodium drops from the hot-leg pipe into RV, and the RV sodium level rises for certain level because of the sodium drop. The flow amount from RV upper pipes, and time for recognition, judgement, and operation by operators were given as input data.

\subsection{Validations for the program}

For the validation of the program, the leak flow rate in PHTS that was obtained by the calculation program was compared with that in DBA analysis which was obtained by a code, "HIPRAC-III" (PNC, 1985).

Figure 5 shows the comparison about the leak rates. The leakage occurred in the condition of nominal pump operation, and after the leakage, the pump mode changed to that of pony motor with a low-speed. A single pipe crack of size $t^{2}$ in $\mathrm{RV}$ inlet was assumed in them.

The difference of leak rates between them was quite small, and the result of the calculation program was a little bit conservative than that of DBA analysis. Note that the flow rate declining curve by the pump and sodium inertia was not modeled in this program.

\section{Results and discussions}

The calculation result by the program is discussed below. The case with crack size of $t^{2}$ is shown in section 5.1, and that of $D t / 4$ is in section 5.2 .

\subsection{Nominal case}

\subsubsection{Calculation conditions}

The event sequences of the two cases which were chosen in section 2.2 are shown in Fig. 6. Calculation conditions in detail are listed in Table 3. For the leakage in pump inlet, the sodium level declining in RV can be stopped by siphon-breaking. The time interval between the first and second coolant leakages was set 24 hours as mentioned in section 2.3. The effect by the negative pressure below the atmospheric pressure which can raise the RV sodium level was not taken into account conservatively. 
Table 3 Calculation conditions for the two cases.

\begin{tabular}{|c|c|c|c|}
\hline \multicolumn{2}{|r|}{ Items for calculation conditions } & Case-A & Case-B \\
\hline \multirow[b]{2}{*}{$\begin{array}{l}\text { Initial plant } \\
\text { condition }\end{array}$} & Reactor state & \multicolumn{2}{|l|}{ Rated power } \\
\hline & $\begin{array}{l}\text { Hot/cold-leg PHTS sodium temperature, RV } \\
\text { sodium level }\end{array}$ & \multicolumn{2}{|l|}{$529^{\circ} \mathrm{C} / 397^{\circ} \mathrm{C}$, NsL } \\
\hline \multirow{3}{*}{$\begin{array}{l}\text { First coolant } \\
\text { leakage }\end{array}$} & Occurrence time & \multicolumn{2}{|l|}{ Start of elapsed time as a definition } \\
\hline & \begin{tabular}{|l|l} 
Position \\
\end{tabular} & RV inlet in GV of C-loop & Pump inlet in GV of A-loop ${ }^{* 1}$ \\
\hline & $\begin{array}{l}\text { Pipe crack size, coefficient of leakage flow } \\
\text { resistance }\end{array}$ & \multicolumn{2}{|l|}{$D t / 4, C=1.7$} \\
\hline \multicolumn{2}{|l|}{ Trigger for scram } & \multicolumn{2}{|l|}{ Low sodium level in RV } \\
\hline \multicolumn{2}{|c|}{ Trigger for closure of cover-gas system } & \multicolumn{2}{|l|}{ Low sodium level in RV } \\
\hline \multirow{5}{*}{$\begin{array}{l}\text { Procedures before } \\
\text { second leakage }\end{array}$} & Pump of PHTS & $\begin{array}{l}\text { Stop of pony motor of one-loop } \\
\text { (three to two) }\end{array}$ & $\begin{array}{l}\text { Stop of pony motor of one-loop } \\
\text { (three to two) }\end{array}$ \\
\hline & $\begin{array}{l}\text { Required time of sodium melting for siphon- } \\
\text { breaking }\end{array}$ & $\begin{array}{l}\begin{array}{l}\text { Eight hours (whole loops } \\
\text { simultaneously) }\end{array} \\
\end{array}$ & Eight hours (only for leakage loop) \\
\hline & Required time for Siphon-breaking operation & (no operation required) & 15 minute \\
\hline & $\begin{array}{l}\text { Sodium amount per one loop into RV from hot- } \\
\text { leg and IHX upper part by siphon-breaking }\end{array}$ & - & $35 \mathrm{~m}^{3}$ \\
\hline & Sodium charge for sodium-tank & (no operation required) & Drained sodium from leakage loop \\
\hline \multirow{6}{*}{ Second leakage } & Reactor state & \multicolumn{2}{|l|}{ Cold standby } \\
\hline & Hot/cold-leg PHTS sodium temperature & \multicolumn{2}{|l|}{$200^{\circ} \mathrm{C}$} \\
\hline & \begin{tabular}{|l|} 
Occurrence time \\
\end{tabular} & \multicolumn{2}{|l|}{24 hour from first leakage } \\
\hline & Position & Pump inlet in GV of B-loop & RV inlet in GV of C-loop \\
\hline & $\begin{array}{l}\text { Pipe crack size, coefficient of leakage flow } \\
\text { resistance }\end{array}$ & \multicolumn{2}{|l|}{$D t / 4, C=1.7$} \\
\hline & Cover-gas pressure & \multicolumn{2}{|l|}{ Atmospheric } \\
\hline \multirow{3}{*}{ Sodium pump-up } & Trigger for operator recognition & \multirow{2}{*}{\multicolumn{2}{|c|}{$\begin{array}{l}\text { High sodium level in GV } \\
\text { Around EsL }\end{array}$}} \\
\hline & Trigger for interlock system & & \\
\hline & Pump-up rate & $60 \mathrm{~m}^{3} / \mathrm{h}$ (two EMP) & $\begin{array}{l}25 \mathrm{~m}^{3} / \mathrm{h} \text { (through ADHRS } \\
\text { pipe by one EMP) }\end{array}$ \\
\hline \multirow{4}{*}{ Siphon- breaking } & Trigger for operator recognition & High sodium level in GV & (no operation required) \\
\hline & $\begin{array}{l}\text { Required time for Siphon-breaking operation by } \\
\text { operators }\end{array}$ & 15 minute & (no operation required) \\
\hline & $\begin{array}{l}\text { Sodium amount per one loop into RV from hot- } \\
\text { leg and IHX upper part by siphon-breaking }\end{array}$ & $35 \mathrm{~m}^{3}$ & (no operation required) \\
\hline & Pump of PHTS & $\begin{array}{l}\text { Stop of pony motor of leakage loop } \\
\text { before siphon-breaking (from two to } \\
\text { one motors) }\end{array}$ & - \\
\hline
\end{tabular}

\subsubsection{Calculation results \\ 5.1.2.1 Case-A}

The calculation results in Case-A about sodium level in RV, that in GV, leak rate after the second coolant leakage, and flow rate of pump-up are shown in Fig. 7.

The sodium level in RV declined close to EsL after the first leakage in RV inlet, beginning from initial sodium level of normal sodium level (NsL). On the other hand, the sodium level in RV-GV rose to SsL. The SsL which corresponds to the upper edge of GV is determined by the GV sodium level after the first leakage within DBA. The sodium level difference between RV and SsL corresponds to the pump head by the pony motor in three loops. The sodium pump-up is conducted intermittently and automatically until the cold standby.

The RV sodium level declined again after the second leakage in pump inlet. When the RV sodium level approached around the preset value around EsL, the pump-up system was activated automatically by the interlock system. The RV sodium level was maintained by the intermittent pump-up. After the operator recognition of the second leakage by an alarm of high sodium level in pump-GV, sodium melting for siphon-breaking started. The sodium level was raised by sodium inflow from upper pipes by the siphon-breaking. The leakage stopped, and sodium level reached final steady state after that.

\subsubsection{Case-B}

The calculation result of Case-B is shown in Fig. 8. The sodium level in RV declined to SsL; the sodium level in pump-GV rose to SsL by the first coolant leakage. The sodium melting was started when it reached the cold standby, and eight hours later which was necessary for the melting, the siphon-breaking was done for the leakage loop. The sodium level was raised by the sodium inflow from upper pipes after the siphon-breaking.

After the second leakage, the sodium level declined, and when it approached around EsL, the sodium pump-up was activated by the interlock system intermittently. When the sodium level in RV-GV rose to high level, the leakage is terminated, and it reached the final steady state. 


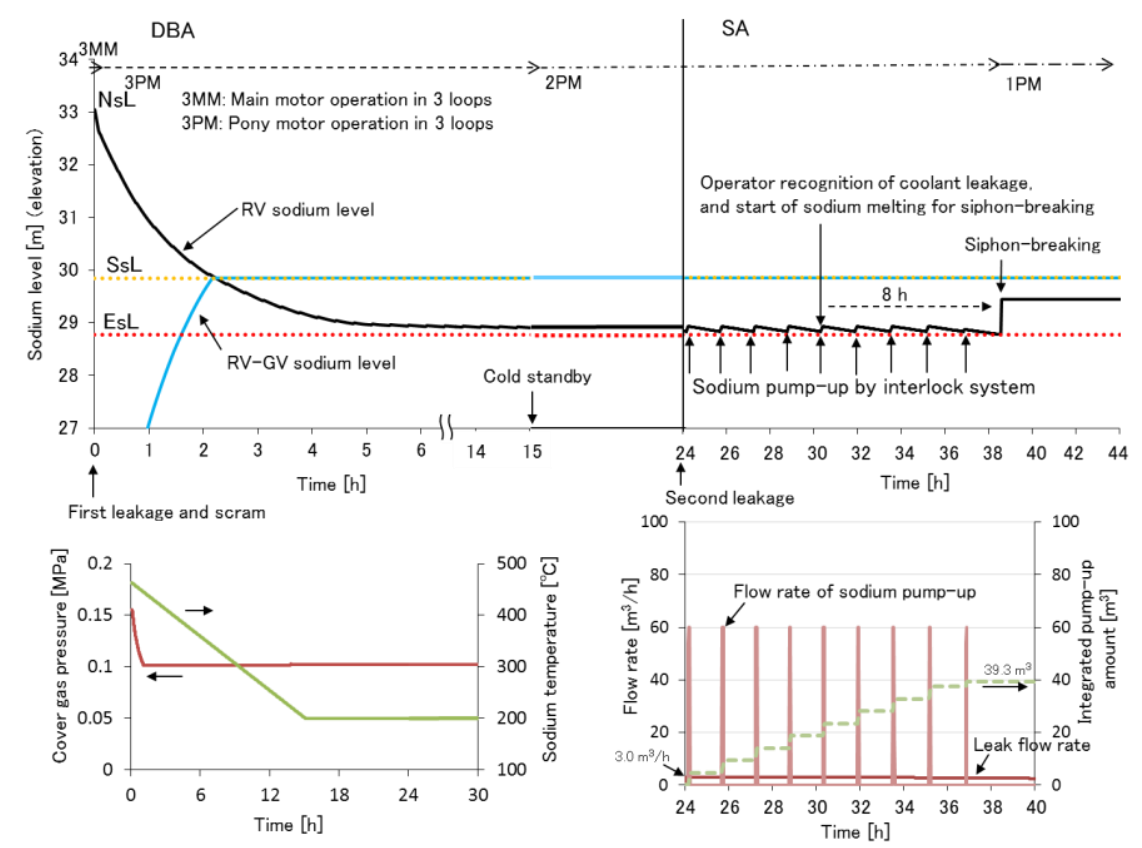

Fig. 7 Calculation result of case-A.

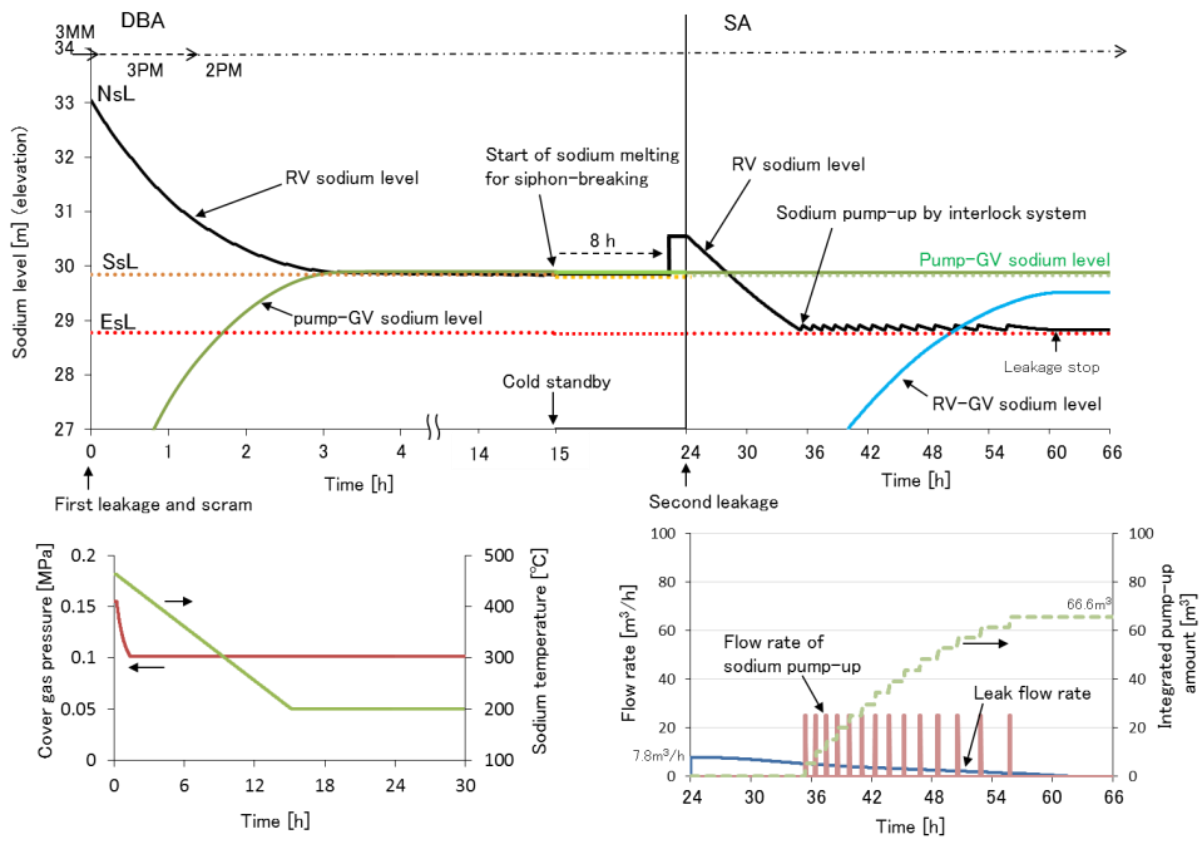

Fig. 8 Calculation result of case-B.

In this case, the pump-up by the over-flow system was not available because one of the rooms of the leakage loop shares same room with that of the over-flow system. Thus, the pump-up was conducted by a single electromagnetic pump through the pipe of ADHRS. The sodium of sufficient amount for the continuous pump-up became available by draining primary loop of the leakage or secondary loop of the siphon-breaking and transferring that into the sodium-tank.

\subsection{The cases for larger crack size}

To survey the effect for countermeasures for the case of larger crack size, the crack of size of $D t / 4$ which was assumed in DBA analyses was assumed below for the second leakage. The capability of these parameter surveys about the countermeasure is one of the advantages of this calculation program. 


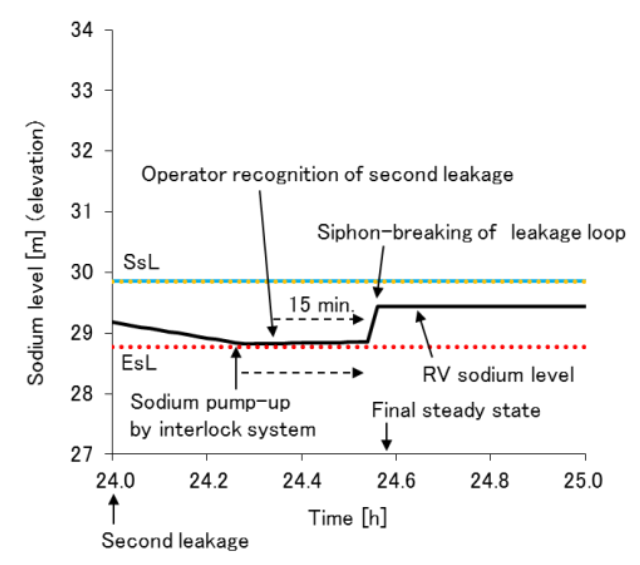

Fig. 9 The case of larger crack size for case-A.

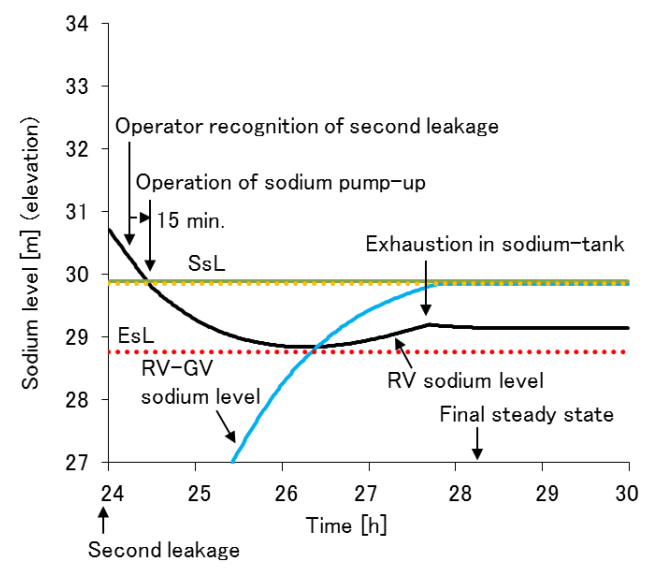

Fig. 10 The case of larger crack size for case-B.

\subsubsection{Case-A}

The result of the parameter survey for case-A is shown in Fig. 9. Due to the fast declining speed of RV sodium level after the second leakage, the melting for siphon-breaking must be done for all three loops before the second leakage in this case. Owing to this preparation, the siphon-breaking was done immediately after the second leakage only with the time for operator recognition of the leakage loop by the leakage alarm of pump-GV. After the siphon-breaking, the outflow from RV stopped, and it reached the final steady state.

\subsubsection{Case-B}

The result of the parameter survey for case-B is shown in Fig. 10. In this case, RV sodium level has to be raised as high as possible by the sodium pump-up before the second leakage, not only by the siphon-breaking. In addition, the pump-up after the second leakage must be started immediately after the leakage recognition. Note that sodium in primary and secondary loops must be drained and transferred to the sodium tank for the pump-up into RV as well as the nominal case above.

\section{Conclusions}

An evaluation method for loop-type SFR was developed for severe accidents which were initiated by second coolant leakages in PHTS.

By the calculation program which was developed in this study, the sodium level transient when the second coolant leakage occurred was calculated quantitatively for Monju considering the effect by countermeasures such as sodium pump-up and siphon-breaking operation.

As a result, it was evaluated that LORL sequence after the second coolant leakage where the sodium level declines below EsL can be prevented even in the situations after the second coolant leakage, when the countermeasures for sodium level retention above EsL was taken into account.

Furthermore, the effects by the difference of the crack size were also surveyed by the calculation program which can handle and include effects by the countermeasures. By that survey, it was revealed that some preparations of countermeasures such as sodium pump-up or siphon-breaking are necessary to be completed before second leakage, for prevention of sodium level declining below EsL.

\section{Acknowledgments}

As for PRA, intensive work by K. Kurisaka (JAEA) was very supportive. Furthermore, valuable advices which were given from K. Ichikawa (MFBR), K. Yoshimura (JAEA), and R. Nakai (JAEA) are deeply appreciated. 


\section{References}

Advisory Committee on Monju Safety Requirements, Safety requirements expected to the prototype fast breeder reactor "Monju", JAEA-Evaluation 2014-005 (2014), (in Japanese).

Daniel Garcia-Rodriguez, Yasuhide Sakakibara, "Fatigue crack propagation experimental evaluation and modeling in an austenitic steel elbow from a LMFBR primary system piping”, ASME 2014 Pressure Vessels \& Piping Conference (2014).

IAEA, Primary coolant pipe rupture event in liquid metal cooled reactors, IAEA-TECDOC-1406 (2004).

Idelchik, I.E., Handbook of hydraulic resistance, 2nd ed., Hemisphere Publishing Corp. (1986).

Ishikawa, K., Takamatsu, M., Kawahara, H., Mihara, T., Kurisaka, K., Terano, T., Murakami, T., Noritsugi, A., Iseki, A., Saito, T., Aoyama, T., Probabilistic safety assessment on experimental fast reactor Joyo; Level1 PSA for internal events, JAEA-Technology 2009-004 (2009), (in Japanese).

Kumar, V., et.al, An engineering approach for elastic-plastic fracture analysis, EPRI NP-1931 (1981).

Kurisaka, K., Development of component reliability database for an LMFBR, PNC technical review, No.98, p.18-31, (1996) (in Japanese).

Kurisaka, K., Probabilistic safety assessment of Japanese sodium-cooled fast reactor in conceptual design stage, 15th Pacific Basin Nuclear Conference, Sydney, Australia (Oct. 15-20, 2006) Paper 326.

Kurisaka, K., Study on preliminary level-1 PSA for Japan sodium-cooled fast reactor, Workshop on PSA for new and advanced reactors, NEA/CSNI/R(2012)2 (2012), pp.61-70.

Monju Project Management and Engineering Center, International review on safety requirements for the prototype fast breeder reactor "Monju", JAEA-Evaluation 2015-013 (2015).

PNC, Computer codes for safety analysis of LMFBR, PNC TN241 85-12 (1985), pp.61-74, (in Japanese).

U.S. Nuclear Regulatory Commission, "Standard Review Plan", NUREG-75/087, Section 3.6.1 (1990).

Yamada, F., Fukano, Y., Nishi, H., Konomura, M., Development of natural circulation analytical model in Super-COPD code and evaluation of core cooling capability in Monju during a station blackout, Nuclear Technology, Vol.188, No.3, pp.292-321 (2014)

Yamada, F., Arikawa, M., Fukano, Y., Validation of core cooling capability analysis in Monju during guillotine pipe break at primary heat transport system, International conference of nuclear energy (ICONE23), 1205 (2015). 